\title{
La tipificación del contrato de suministro de contenidos y servicios digitales: entre la propiedad intelectual y el derecho de consumo
}

The typification of the contract for the supply of digital contents and services: between copyright and consumer law

\author{
Juan Pablo Aparicio Vaquero \\ Profesor Titular de Derecho Civil \\ Universidad de Salamanca \\ E-mail: juanpa@usal.es
}

\begin{abstract}
Resumen: La calificación de los contratos de suministro de contenidos y servicios digitales es conflictiva, y no se ha llegado a una solución uniforme. De hecho, podríamos decir que no hay ninguna solución al respecto en el Derecho de consumo (que regula sin más la situación del consumidor con independencia del tipo contractual), y que aun dentro del propio ámbito de la propiedad intelectual, hay importantes incongruencias, cuando no auténticas contradicciones. El TJUE ha desarrollado una jurisprudencia que consagra una duplicidad de regímenes entre los programas de ordenador y el resto de obras digitales. En el presente estudio se realiza un análisis de la situación actual, con ciertas propuestas de lege ferenda que pasan por una necesaria modificación de algunas normas del Derecho de propiedad intelectual.
\end{abstract}

Palabras clave: Derecho de consumo, propiedad intelectual, tipo contractual, derecho de distribución, derecho de comunicación pública, conformidad. 


\begin{abstract}
The qualification of contracts for the supply of digital contents and services is conflictive, and no uniform solution has been reached. In fact, we could say that there is no solution in this respect in Consumer law (which simply regulates the situation of the consumer regardless of the type of contract), and that even within the scope of Copyright itself, there are significant inconsistencies, if not real contradictions. The European Court of Justice has developed a doctrine that establishes a duplication of regimes between computer programs and other digital works. This study deals with the current situation, with certain proposals de lege ferenda which include a necessary modification of some Copyright rules.

Keywords: Consumer Law, Copyright, contractual type, distribution right, right of public communication, conformity.
\end{abstract}

Sumario: 1. La concurrencia de normativas con diferentes principios y objetos en la comercialización de los contenidos y servicios digitales. 2. Los contratos de suministro de contenidos digitales en el Derecho de consumo. 3. Los contratos de suministro de contenidos digitales en el Derecho de propiedad intelectual. 4. Propuesta de unificación de los tipos contractuales en el suministro de contenidos digitales. 4.1. Sobre los contratos onerosos de prestación única. 4.2. Sobre los contratos onerosos temporales de prestación continuada o sucesiva. 5. Conclusiones. 6. Bibliografía.

\title{
1. La concurrencia de normativas con diferentes principios y objetos en la
} comercialización de los contenidos y servicios digitales

En ocasiones, el ordenamiento jurídico resulta inconsistente, como sucede en el caso de los contenidos y servicios digitales, en que no solo no queda claro cuál es el tipo contractual conforme al cual se suministran al consumidor (y, por lo tanto, la posición de este respecto de aquellos), sino que hay divergencias entre las ramas implicadas (consumo y propiedad intelectual) e, incluso, contradicciones internas en sus respectivos ámbitos. Sin duda, el origen de la problemática se encuentra en los principios que inspiran ambas normativas, y quién es el sujeto principal destinatario de su protección: consumidor (frente al empresario) y autor-titular de los derechos sobre la obra. 


\begin{abstract}
El autor (o titular de derechos afines, como artistas o ejecutantes) es protegido frente a los cesionarios (contractuales o ex lege) que se convierten, en virtud de dicha cesión, en titulares de los derechos de explotación y que, por lo tanto, son quienes comercializan la obra o prestación protegida: el escritor frente a la editorial a la que cede su obra y que la edita y vende ejemplares al público. Tradicionalmente, el titular de los derechos de explotación se veía protegido frente a ciertas pretensiones de los autores (por ejemplo, ante el ejercicio de ciertos derechos morales, como el de retirar la obra del comercio), pero no frente a los destinatarios, frente a quienes solo veía limitados sus derechos, por diferentes razones: de orden público, (difusión de la cultura), económico (agotamiento de su derecho de distribución) o imposibilidades prácticas de control (copia para uso privado); y aun así, en ocasiones, con compensaciones. La protección frente a los destinatarios se articulaba desde la persecución, civil o penal, de las infracciones a su exclusiva (p. ej., la llamada piratería). Sin embargo, en la concepción moderna, la política legislativa tiende al refuerzo de la posición del titular de los derechos frente a los destinatarios de las obras también desde la redefinición de tales derechos, al tiempo que, de otro lado, también a ellos se les reconocen derechos, como sucede en el ámbito del Consumo e, incluso, en sede de propiedad intelectual, como auténticos sujetos de derechos. El desencadenante de un cambio de tal entidad ha sido, sin duda, el progreso tecnológico y la aparición del formato digital, que ha permitido la explotación de obras a través de Internet.
\end{abstract}

Al legislador de consumo le interesa el contenido (digital) en cuanto objeto del comercio en orden a la protección de los intereses del consumidor adquirente (o usuario del servicio). El legislador en sede de propiedad intelectual persigue la protección del titular de los derechos sobre la obra objeto de explotación, interpretando las cesiones de derechos sobre la misma en sentido restrictivo y, por lo tanto, afectando a la posición de la contraparte, su destinatario, en la terminología tradicional al uso en esta sede; por lo que ahora importa, tal destinatario es el consumidor o usuario del contenido o servicio digital que es, a la vez, obra o prestación objeto de protección.

En el ámbito del consumo, nunca ha sido relevante (desde luego, no esencial) articular la transmisión de derechos de propiedad intelectual al consumidor o usuario, por cuanto éste no los necesitaba para disfrutar, p. ej., de un libro, una vez adquirido el ejemplar; y cuando los ha necesitado (para el disfrute de los contenidos digitales), la norma ha podido prescindir de toda calificación jurídica, habida cuenta de la complejidad técnica de la cuestión y sus derivadas para otras ramas del ordenamiento, bastándole con otorgar al consumidor un alto nivel de protección que compensara su situación de inferioridad respecto del empresario ${ }^{1}$.

\footnotetext{
${ }^{1}$ En la STJUE de 5 de marzo de 2020, C-679/18, OPR-Financie s.r.o. c. GK, el TJUE recuerda que la posición de inferioridad es el fundamento del sistema de protección, "tanto en lo referente a la capacidad de negociación como al nivel de información, que le lleva a adherirse a las condiciones redactadas de antemano por el profesional, sin poder influir en el contenido de las mismas" (apdo. 19). Las normas de consumo a las que se alude en el presente estudio tienen por finalidad, precisamente, compensar la falta de conocimientos del consumidor (en general y en lo relativo a los contenidos y servicios digitales) regulando la forma y contenido de la información a suministrar por el profesional, así como restaurar el equilibrio contractual frente a las conductas incumplidoras y las cláusulas exoneradoras de responsabilidad impuestas,
} 
Tampoco en sede de propiedad intelectual fue nunca necesario regular los derechos de quien simplemente disfrutaba de la obra, pues dicho goce en nada afectaba a los del titular que la explotaba.

\begin{abstract}
Leer un libro o escuchar música grabada en un vinilo o un casete musical analógico (en soporte magnético) no suponen "reproducción" del ejemplar objeto de disfrute en sentido técnico jurídico, por más que la música o la película hayan de ser introducidas en un "reproductor" que descodifica las señales grabadas en la cinta para recuperar los sonidos o imágenes.
\end{abstract}

La relación entre el usuario (adquirente, espectador) y la obra venía configurada, a lo sumo, por límites a los derechos de autor: así, el de copia para uso privado o la posibilidad de revender el ejemplar adquirido, merced al agotamiento del derecho de distribución del titular. Sucede, sin embargo, que, con la aparición de los formatos digitales, tal disfrute trae consigo necesariamente la realización por parte del usuario de actos que afectan a determinados derechos de exclusiva de los titulares de las obras (su reproducción, en sentido jurídico); a ello se suma que permiten nuevas formas de explotación y lesión de tales derechos y que, además, los propios usuarios pueden generar masivamente contenidos protegidos que son objeto de explotación comercial por terceros. El legislador tuvo en cuenta algunas de estas cuestiones al regular la obra/contenido digital paradigmática (los programas de ordenador), reconociendo por primera vez auténticos derechos al usuario (art. 100 TRLPI) ${ }^{2}$, junto con ciertas especialidades en su explotación (al menos, como se verá, en interpretación del TJUE), pero no ha extendido este régimen (ni lo ha hecho la mencionada interpretación judicial) al resto de obras en formato digital.

La segunda cuestión relevante es la de la terminología empleada por ambas ramas del ordenamiento, que apuntan a que los objetos de regulación no son plenamente coincidentes. Las expresiones contenido digital y servicio digital (ambas, de utilización más frecuente en plural) son propias del Derecho de consumo, no de la propiedad intelectual, aunque ya empiezan a tener reflejo en esta; mas ni aun así son utilizadas en el mismo sentido en ambos campos. Tampoco el término servicios tiene un sentido unívoco en estas normas y en las propias de los servicios de la Sociedad de la Información (SI).

obligando al proveedor a asumir unos estándares de cumplimiento (“conformidad"); la última gran cuestión tratada es el derecho de desistimiento, derivado de la contratación en línea (a distancia).

${ }^{2}$ Real Decreto Legislativo 1/1996, de 12 de abril, por el que se aprueba el Texto Refundido de la Ley de Propiedad Intelectual, regularizando, aclarando y armonizando las disposiciones legales vigentes sobre la materia. 
En la normativa de consumo (arts. 2.11 $\mathrm{DDC}^{3}$; arts. 2.1 $\mathrm{DCSD}^{4}$; art. 2.6 $\mathrm{DCB}^{5}$; y art. 59 bis $1 d$ TRLGDCU $^{6}$ ), los contenidos digitales son datos producidos y suministrados en formato digital: entre otras cosas, dice el Cdo 19 DCSD, se refieren a programas informáticos, aplicaciones, archivos de vídeo, archivos de audio, archivos de música, juegos digitales, libros electrónicos u otras publicaciones electrónicas (en la misma línea, Cdo 19 DDC; GARROTE FERNÁNDEZ-DÍEZ, I., 2013, 753, sobre las incorrecciones en que incurren tanto la definición como estos ejemplos).

En este contexto, además, la expresión "contenido" puede ser sinónimo genérico de producto, objeto de comercialización, aunque para mayor precisión (p. ej., en sede de obligación de entrega o garantías), el art. 59 bis 2 TRLGDCU aclara que el concepto de bien se refiere a las cosas muebles corporales, por lo que en otros preceptos se menciona cumulativamente a los bienes (que se entregan) y a los contenidos o servicios digitales (que se suministran): así, arts. 66 bis o 115 ss TRLGDCU.

Por su parte, el servicio digital aparece definido por primera vez en el art. 2.2 DCSD, art. 2.7 DCB y art. 59 bis 1 o TRLGDCU, como aquel que permite al consumidor o usuario crear, tratar, almacenar o consultar datos en formato digital, o un servicio que permite compartir datos en formato digital cargados o creados por el consumidor $\mathrm{u}$ otros usuarios de ese servicio, o interactuar de cualquier otra forma con dichos datos ${ }^{7}$.

\footnotetext{
${ }^{3}$ Directiva 2011/83/UE del Parlamento Europeo y del Consejo, de 25 de octubre de 2011, sobre los derechos de los consumidores, por la que se modifican la Directiva 93/13/CEE del Consejo y la Directiva 1999/44/CE del Parlamento Europeo y del Consejo y se derogan la Directiva 85/577/CEE del Consejo y la Directiva 97/7/CE del Parlamento Europeo y del Consejo. Tras su modificación por la Directiva (UE) 2019/2161, la definición se produce por simple remisión a la Directiva 2019/770.

${ }^{4}$ Directiva (UE) 2019/770 del Parlamento Europeo y del Consejo, de 20 de mayo de 2019, relativa a determinados aspectos de los contratos de suministro de contenidos y servicios digitales.

${ }^{5}$ Directiva (UE) 2019/771 del Parlamento Europeo y del Consejo, de 20 de mayo de 2019, relativa a determinados aspectos de los contratos de compraventa de bienes, por la que se modifican el Reglamento (CE) n. ${ }^{\circ}$ 2017/2394 y la Directiva 2009/22/CE y se deroga la Directiva 1999/44/CE.

${ }^{6}$ Real Decreto Legislativo 1/2007, de 16 de noviembre, por el que se aprueba el Texto Refundido de la Ley General para la Defensa de los Consumidores y Usuarios y otras leyes complementarias. Su última reforma, que afecta a conceptos que aquí manejamos, ha sido por RD-Ley 7/2021, de 27 de abril, con entrada en vigor el 1 de enero de 2022.
}

${ }^{7}$ Se añadió esta definición a la DDC, por remisión a la Directiva (UE) 2019/770, por la citada Directiva (UE) 2019/2161 (art. $4.1 e$ ), junto con otros conceptos. 
Ambas concepciones son deliberadamente amplias; la de contenido digital permite prescindir del medio o soporte en el que se encuentran guardados o almacenados tales contenidos, siendo lo relevante la forma en que son suministrados (no tanto, producidos) a la contraparte (consumidor) los datos: digitalmente, en forma de bits, estados binarios, unos y ceros que son leídos por los dispositivos electrónicos que los envían, reciben o permiten su disfrute. Y la de servicio digital comprende también los casos en los que son los usuarios de tales servicios de tratamiento, almacenamiento, consulta o provisión de contenidos digitales los que los crean, suben o comparten.

El término contenido era, en principio, ajeno a la propiedad intelectual, en el que la tradicional regulación tiene por objeto la obra y, a lo sumo, las prestaciones protegidas. Por lo que ahora interesa, una obra es una creación literaria, artística o científica, esto es, la forma que adopta y mediante la cual se exterioriza una idea en cualquiera de tales ámbitos. Si dicha obra es, además, original, resultará protegida por el ordenamiento, reconociéndose a su autor una serie de derechos de diversa índole (moral y económicos o de explotación) sobre la misma. Obsérvese que la protección no deriva de la mera existencia de la obra o creación, sino del cumplimiento de un requisito jurídicamente evaluable: su originalidad (art. 10.1 TRLPI), sea cual sea el concepto que se tenga de esta o que sea aplicable según el tipo de obra. En esta sede, la expresión contenido digital, a salvo alguna mención previa ${ }^{8}$, es utilizada en la Directiva (UE) 2019/790 de Derechos de autor en el mercado digital (DAMU) ${ }^{9}$, pero teniendo claro que es un concepto distinto

\footnotetext{
${ }^{8}$ Tres referencias genéricas y no significativas en los Cdos de la Directiva 2001/29/CE del Parlamento Europeo y del Consejo, de 22 de mayo de 2001, relativa a la armonización de determinados aspectos de los derechos de autor y derechos afines a los derechos de autor en la sociedad de la información (Directiva de Derechos de Autor en la Sociedad de la Información, DDASI).
}

\footnotetext{
${ }^{9}$ Directiva (UE) 2019/790 del Parlamento Europeo y del Consejo, de 17 de abril de 2019, sobre los derechos de autor y derechos afines en el mercado único digital y por la que se modifican las Directivas 96/9/CE y 2001/29/CE. En esta se habla repetidamente de contenidos (culturales, educativos...), "también en el entorno digital" (Cdo 2) o "disponibles" o "puestos a disposición del público en línea" (Cdos 14, 18, etc.) en un sentido muy parecido al de la normativa de consumo, en cuanto bienes objeto de mercado. Y, concretando aún más (Cdos 61 y ss.), se profundiza en la problemática y régimen de los "servicios para compartir contenidos u otras prestaciones protegidos por Derechos de autor cargados por sus usuarios". En algún caso, a semejanza de la tradicional expresión "obras y otras prestaciones", repetidamente utilizada, se utiliza otra, "contenidos y otras prestaciones" (Cdo 62), por lo que parece que, a determinados efectos (los de puesta a disposición del público de creaciones en forma digital a través de estos servicios) "contenidos" y "obras" son hasta cierto punto sinónimos (o términos intercambiables), en el bien entendido que ambos se refieren a los que cumplan los requisitos para su protección en sede de PI; en este sentido, en el propio art. 1, al definir su objeto, la Directiva afirma pretender la armonización de los Derechos de Autor y afines teniendo en cuenta los usos digitales y transfronterizos de "los contenidos protegidos"; al final del párrafo se vuelve a utilizar la más correcta expresión "obras y otras prestaciones".
} 
y más amplio, como pone de manifiesto, p. ej., al definir "prestador de servicios para compartir contenidos en línea" (art. 2.6): un prestador de servicios cuyo fin principal (o uno de ellos) es almacenar y dar al público acceso a una gran cantidad de obras u otras prestaciones protegidas. El fin principal del prestador de servicios regulado es dar acceso a obras y prestaciones protegidas, con independencia de que dé acceso, también, a contenidos de otro tipo, no sujetos a normas de propiedad intelectual.

Así pues, en nuestro ordenamiento, el concepto de "contenido" es más amplio que el de obra (creación intelectual protegida), pero son coincidentes en los supuestos que resultan ser económica y jurídicamente más relevantes: obsérvese que todos los ejemplos de contenidos que dan los Cdos de las DDC y DCSD no solo son susceptibles de ser obras protegidas, sino que, en su mayor parte, lo son en cada categoría, y sostienen importantes sectores de la economía y el comercio en los ámbitos tecnológicos (programas informáticos), científicos, culturales y de ocio.

Desde el punto de vista contractual (los negocios que, sirviendo a la explotación comercial de estos contenidos digitales, permiten a los consumidores su disfrute), no hay interferencia ninguna entre el Derecho de consumo y el de propiedad intelectual cuando tales contenidos resultan ser creaciones no protegidas por la causa que sea (en cuyo caso, nada importan al Derecho de propiedad intelectual): obras no originales o expresamente excluidas de protección (arts. 13 y 96.3 in fine TRLPI). Existe cierto grado de concurrencia, aunque menor, en aquellos casos en que la tutela jurídica por derechos de autor o afines ya ha expirado o en los que el titular de derechos los ha abandonado o ha explotado la obra en forma gratuita y libre; en estos casos, la pervivencia de los derechos morales es la que mantiene la aplicabilidad de la PI, pero en general no se afecta a su comercialización.

Pero sí hay una necesaria confluencia y relación entre ambas ramas del ordenamiento jurídico en aquellos casos en que los contenidos digitales objeto de suministro a los consumidores son, a su vez, obras y prestaciones protegidas. Ello obliga, por ejemplo, a valorar la legitimidad del proveedor en orden a garantizar su pacífico disfrute, en cuanto titular de los derechos que transmite, o que está autorizado para hacerlo: así, el empresario es responsable frente al consumidor de la falta de conformidad derivada de la vulneración de derechos de terceros, en particular, de derechos de propiedad intelectual (arts. 10 
DCSD y 117.2 TRLGDCU).

Y la citada concurrencia puede llegar al aparente conflicto cuando se trata de calificar los contratos por los cuales se suministran a los consumidores tales contenidos, dadas las diferentes e imprecisas terminologías manejadas por el legislador y los empresariossuministradores-titulares en ambas sedes: ¿suministro? ¿compraventa? ¿contrato de servicios? ¿arrendamientos? ¿licencias? Las consecuencias jurídicas de estar ante uno u otro tipo contractual son importantes, al menos en sede de propiedad intelectual y pervivencia de los derechos de exclusiva del titular, como más adelante se detalla.

Tampoco coincide la terminología del Derecho de propiedad intelectual y el Derecho de consumo con la del comercio electrónico: DCE y LSSI ${ }^{10}$ : “servicios”, en esta, es un modo genérico de denominar los negocios en la red (“servicios de la SI"), sin la menor intención de tipificación contractual, mientras que en aquellas apunta a una mayor concreción, por contraposición con la compraventa; en la DCE tienen cabida, bajo esta denominación, todo tipo de negocios, incluida la venta de bienes y productos, mientras que en el Derecho de consumo y de propiedad intelectual, los servicios (digitales) son aquellas actuaciones comerciales o de explotación de derechos en un sentido que, sin ser del todo el tradicional jurídico contractual (como se utiliza en la expresión: contrato o arrendamiento de servicios) implica la realización de prestaciones de hacer (sobre todo) distintas de la mera entrega (y consiguiente transmisión de la propiedad) en que consiste la compraventa.

En definitiva, la explotación comercial de los derechos de propiedad intelectual a través de internet (mediante la distribución de ejemplares o la comunicación pública de obras o prestaciones protegidas), de un lado, y la comercialización de contenidos y servicios digitales, de otro, son servicios de la sociedad de la información, sea cual sea la forma jurídico contractual que adopte dicha actividad: compraventa, suministro, licencia (cesión limitada de derechos de uso), alquiler o contrato (arrendamiento) de servicios.

\footnotetext{
${ }^{10}$ Directiva 2000/31/CE del Parlamento Europeo y del Consejo, de 8 de junio de 2000, relativa a determinados aspectos jurídicos de los servicios de la sociedad de la información, en particular el comercio electrónico en el mercado interior (Directiva sobre el Comercio Electrónico); y Ley 34/2002 de 11 de julio de Servicios de la Sociedad de la Información y de Comercio Electrónico.
} 


\section{Los contratos de suministro de contenidos digitales en el Derecho de consumo}

El término suministro (supply, en sus versiones en inglés) que utiliza la normativa de consumo (DDC, DCSD y TRLGDCU), tiene un doble sentido: de una parte, una forma simple de aludir a la comercialización o provisión de bienes y servicios, sin mayor pretensión de tipificación contractual, englobando a cualesquiera negocios (típicos o atípicos: compraventa, alquiler, licencia, contrato de servicios, etc.) mediante los cuales el empresario provee de los contenidos y servicios digitales al consumidor. De otra, un auténtico contrato que, aun siendo atípico ${ }^{11}$, es definido por doctrina y jurisprudencia como aquel que consiste en el intercambio de prestaciones duraderas o de ejecución continuada y sucesiva (a cargo del suministrador o proveedor) a cambio de un precio, que pagaría, en este caso, el consumidor o usuario, bien de forma única, bien en períodos determinados o determinables. Sirve así a la satisfacción de intereses o necesidades continuas del destinatario de las prestaciones. Aunque próximo a la compraventa, cuyas normas podrían aplicársele por analogía en lo que exista eadem ratio, se diferencia de esta en que no hay una entrega única de lo suministrado (con abundante jurisprudencia, GRIMALT SERVERA, 2013, 129-131).

¿A cuál de estas dos perspectivas se refiere el legislador del Derecho de consumo cuando regula los derechos del consumidor en el marco de los contratos de suministro de contenidos digitales? Sin duda, a la primera.

El Cdo 19 DDC establecía una distinción entre contenidos y servicios digitales, de manera que consideraba que los primeros, cuando se suministraban sobre un soporte material (CD, DVD, etc.), son bienes a sus efectos, mientras que si no se suministran sobre soporte material, no son objeto de un contrato de compraventa ni de servicios. Apuntaba así a una suerte de tercer tipo contractual (GARROTE FERNÁNDEZ-DÍEZ, 2013, 754-756) o a la necesidad, ante la ausencia de una calificación expresa, de establecer una regulación ad hoc (CÁMARA LAPUENTE, 2014, 93), que parece que es lo que finalmente hizo el

\footnotetext{
${ }^{11}$ Aunque hay una aparente tipificación en el Derecho Público (art. 16 Ley 9/2017, de 8 de noviembre, de Contratos del Sector Público, LCSP), obsérvese que también aquí son una forma de denominar a toda una categoría de contratos más que un concreto tipo contractual, englobando adquisiciones (compraventas), arrendamientos, contratos de fabricación (arrendamiento de obra) e, incluso, licencias o cesiones de uso de programas de ordenador. Los contratos sobre otros bienes incorporales no entran en esta categoría (en realidad, quedan excluidos de la norma y tendrían naturaleza privada), ni tampoco los de desarrollo (creación) de software (expresamente calificados de contratos de servicios, arts. 16.3.b y 17 LCSP).
} 
legislador español, distinguiendo en cada precepto, en su caso, las especialidades oportunas.

Por su parte, y más en concreto, la DCSD sí excluye toda voluntad de tipificación, de forma muy clara (cursivas mías): A pesar de que la Directiva debe aplicarse a cualquier contrato en virtud del cual el empresario suministra o se compromete a suministrar contenidos o servicios digitales al consumidor (Cdo 18), se limita a armonizar (plenamente) aspectos relacionados con la conformidad y suministro de tales contenidos y servicios (Cdo 11), no afectando a otras cuestiones, aun de índole contractual, y tampoco debe determinar la naturaleza jurídica de los contratos de suministro de contenidos o servicios digitales, y la cuestión de si tales contratos constituyen, por ejemplo, un contrato de compraventa, de servicios, de alquiler o un contrato atípico, debe dejarse a la determinación del Derecho nacional (Cdo 12). Como se aprecia, el giro del legislador europeo es radical, contradiciendo los postulados de la Directiva de 2011, debiendo primar la última consideración por cuanto es posterior y especial respecto de la primera: el legislador europeo no califica tales contratos, dejando la cuestión a los legisladores nacionales.

El TRLGDCU no entra tampoco a determinar tal naturaleza jurídica, pero al recoger de forma obligada el concepto de compraventa de la DDC y las Directivas de 2019, hay que realizar una interpretación conforme del mismo con lo previsto en tales normas, en particular, con la primera, que es la que introduce por primera vez la definición de este paradigmático contrato en nuestro ordenamiento.

La Convención de Viena sobre compraventa internacional de mercaderías, de 1980, no contenía propiamente una definición, aunque sí recogía la obligación de transmitir propiedad como principal del vendedor (art. 30); por lo tanto, al entrar en vigor en España en 1991, sentaba tal obligación por primera vez en nuestro ordenamiento.

En su art. 59 bis se definen tanto la compraventa (o venta) como los contratos de servicios (letras $f$ y $g$, respectivamente, tras su modificación de 2021) y, en su interpretación conforme con la citada DDC, apunta a que, siendo considerados bienes (citado art. 59 bis 2, en relación con el 59 bis 1 f), el suministro de contenidos digitales sobre soporte físico destinado exclusivamente a tal fin (entiéndase, entrega de los mismos sin límite temporal a cambio de un precio) es calificable de compraventa aunque no llega a darse legalmente tal tipificación expresa. 


\begin{abstract}
No aclara tampoco la cuestión de la naturaleza el art. 114, en sede de garantías, cuando señala que "Están incluidos en el ámbito de aplicación de este título los contratos de compraventa de bienes existentes o de bienes que hayan de producirse o fabricarse y los contratos de suministro de contenidos o servicios digitales, incluyéndose como tales todos aquellos que tengan por objeto la entrega de soportes materiales que sirvan exclusivamente como portadores de contenidos digitales". ¿A qué se refiere la expresión "incluyéndose como tales": a todos los contratos mencionados o solo a los de "suministro", excluyéndolos de la venta? El precepto es de nueva redacción, de trasposición de las Directivas de 2019, por lo que tendría sentido pensar que no está calificando y sí, sin más, haciendo extensivo el régimen de garantía y conformidad a los suministros de contenidos y servicios digitales, en el sentido no tipificador de las mismas y trasladándolas tal cual, como es habitual por parte de nuestro legislador. Y, como he señalado, la interpretación conforme con la DDC y las definiciones del art. 59 bis llevan fundadamente a pensar que estando el contenido digital sobre soporte físico y dándose las condiciones descritas supra hay compraventa. Al legislador sólo le importa (EM del RD-L 7/2021) que haya una regulación "clara y unificada", con independencia de la naturaleza del contenido o servicio digital; aunque tal afirmación se hace respecto de los objetos de las Directivas 2019/770 y 2019/771, es extensible también a la existencia o no de soporte material: los problemas de conformidad en torno a la funcionalidad, p. ej., son los mismos, de ahí que dicho soporte no sea tenido en cuenta al abordar la cuestión en los arts. 115 y ss. En el art. 104, en cambio, sí hay diferencia en el dies a quo del derecho de desistimiento: el punto $b$ (adquisición de la posesión material) se aplica a los bienes y contenidos digitales sobre soporte físico, mientras que si no existe este se acudiría al $c$ (celebración del contrato). Así, el legislador solo va estableciendo diferencias en los casos que considera oportunos, recibiendo los contenidos digitales sobre soporte el mismo régimen que el resto de bienes.
\end{abstract}

Así las cosas, el suministro de contenidos y servicios digitales, en el ámbito del consumo, parece quedar de la siguiente manera: la prestación de servicios se sujeta a sus propios tipos contractuales, sobre cuya naturaleza nada cabe deducir de estas normas, ni afecta a su régimen; si el contenido digital está fijado sobre un soporte (o forma parte o está conectado con un bien con elemento digital, dispositivo o hardware cuyo funcionamiento hace posible, ex Directiva (UE) 2019/771 y art. 59 bis 1 b TRLGDCU), hay compraventa del mismo, con transmisión de su propiedad si se suministra para su disfrute sin límite temporal a cambio de un precio; pero si, en esas mismas condiciones, el contenido es suministrado por Internet, sin soporte, continuamos en esa indefinición normativa, en la que el tipo (venta, licencia de uso, o alquiler, etc.) le es indiferente al legislador del Derecho de consumo, preocupado solo de garantizar la posición del usuario.

Nos encontramos así con el suministro de unos bienes (los contenidos digitales) que, siendo idénticos, ven alterado su régimen jurídico según se encuentren fijados o no a un soporte material. Esta opción legislativa, aun cuando satisface los intereses de los consumidores en cuanto les reconoce los oportunos derechos (únicos para ambas formas de comercialización, salvo puntuales excepciones derivadas más bien de cómo se celebra el negocio y se produce la entrega) dista mucho de ser óptima y tiene consecuencias para 
otras ramas del ordenamiento, singularmente, la propiedad intelectual, induciendo a confusión a los consumidores (usuarios-destinatarios-público) de las obras protegidas, en cuanto a su situación real (titularidad) respecto del contenido digital adquirido y la posibilidad de su reventa o cesión a terceros adquirentes.

Además, no necesariamente tendría que ser así, ni la normativa de consumo impide realmente la operativa de un tipo contractual distinto, la conocida comercialmente como licencia de uso, aun cuando el contenido digital se suministre sobre un soporte material. Y cabe señalar, por último, la introducción de un nuevo elemento como objeto de intercambio: los datos personales del consumidor/público del contenido/servicio (obra/prestación) digitales. Más allá de lo que ello implica a otros niveles, esta monetización de los datos personales, desde el punto de vista estrictamente contractual, apunta a la revitalización de un primigenio tipo negocial al que la economía de mercado basada en el dinero había dejado a un lado: la permuta. Además, el intercambio de contenidos digitales por datos personales implica también transmisión de la propiedad de aquellos en los mismos términos que la compraventa y, por lo tanto, agota la exclusiva del titular sobre los derechos de propiedad intelectual objeto de comercialización.

\footnotetext{
Este fenómeno (la posible utilización de los datos personales como instrumento de cambio por servicios aparentemente gratuitos) ya fue contemplada por el Supervisor Europeo de Protección de Datos en su Dictamen preliminar sobre intimidad y competitividad en la era de la obtención de datos masivos, de 26 de marzo de 2014 (pp. 10 y 37) y su posterior Dictamen sobre el cumplimiento efectivo de la legislación en la economía de la sociedad digital, de 23 de noviembre de 2016 (p. 6). En su Opinión 4/2017, de 14 de marzo, sobre la Propuesta de Directiva 2019/770 (pp. 8-13), desaconsejó la calificación del contrato de suministro en base a la entrega de datos personales por ser (los datos) algo muy distinto a una simple contraprestación (counter-performance): un derecho fundamental de las personas reconocido como tal en la Carta europea (art. 8) y el Tratado de Funcionamiento de la UE (art. 16), no equiparable al dinero e, incluso, distinto del valor que pueden generar tales datos (que es, además, desconocido para sus titulares consumidores); admitía, no obstante, que tales contratos no eran tan "gratuitos" (con comillas literales) como aparentaban, aunque pedía definiciones que prescindieran del carácter oneroso o gratuito, en la línea de la normativa de Servicios de la sociedad de la información. Frente a semejante postura, es sumamente indicativa la posición final del legislador europeo, que mantuvo la referencia a los datos como contraprestación, de manera que, aunque eliminara la definición de "suministro" como intercambio de servicios "por dinero o datos personales" que contenía la Propuesta, mantiene la existencia de contratos onerosos al margen de la compraventa (con una contraprestación, la entrega de datos personales más allá de lo necesario para la prestación del servicio, distinta del dinero) (sobre el tema: APARICIO VAQUERO, J. P, 2019, 1030-1033; CASTILLO PARRILLA, J. A., 2021; FUENTESCA DEGENEFFE, C., 2018, 109-113; ESPÍN ALBA, I., 2020, 17-22; GARCÍA HERRERA, V., 2020).
} 


\title{
3. Los contratos de suministro de contenidos digitales en el Derecho de propiedad intelectual
}

Frente a las obras tradicionales, explotadas mediante la venta (o alquiler, o préstamo) de ejemplares (la obra sobre un soporte físico: un libro, un disco, una cinta de vídeo, etc.), los programas de ordenador constituyeron un nuevo tipo de obra, la primera de carácter utilitario: un programa no es bonito, agradable o armonioso, sino eficiente, funcional o útil. Los criterios tradicionales de disfrute personal (humano) de las obras no se aplican propiamente a los programas de ordenador, que pueden tener errores, ser objeto de arreglos, mantenimiento, actualizaciones, etc. Y, además, es una obra comercializada en formato digital.

\begin{abstract}
Realmente, el programa de ordenador puede ser expresado en múltiples formas, como impreso en hardware (firmware) o en papel (líneas de código). Pero su utilidad (el desempeño de la función para la que se ha creado) solo es posible cuando consta en formato digital, para su lectura y ejecución por los dispositivos electrónicos. Por lo demás, prescindo aquí de la polémica sede de protección: derecho de patentes, autor, sui generis... La opción por la propiedad intelectual es prácticamente universal y queda recogida en diversos tratados internacionales (OMPI, OMC...).
\end{abstract}

Su copia indiscriminada por los usuarios (tanto para revender como para su uso personal en más dispositivos que los autorizados) causaba importantes pérdidas a las casas de software, que invertían cuantiosas sumas en su desarrollo. Por ello, los titulares de derechos aprovecharon las posibilidades que le ofrecía el legislador para su explotación mediante la simple cesión de derechos de reproducción a efectos de uso, en lugar de la venta de ejemplares, incluso cuando tal obra se comercializaba a través de canales de distribución convencionales, sobre un soporte físico (disquetes, inicialmente; discos compactos como CD o DVD después). Surgieron así las licencias, que adoptaron la forma de shrink-wrap o tear open cuando se dirigieron a los consumidores: se suministraban paquetes con los soportes en el interior y la licencia en el exterior, advirtiendo que el desprecintado suponía la celebración de un contrato de licencia con el usuario final" (CLUF), no propiamente una venta, deviniendo el adquirente usuario, que no propietario de la copia.

No es lugar aquí para discutir la validez, desde el punto de vista contractual, de estas prácticas (vid. al respecto las opiniones encontradas de APARICIO VAQUERO, J.P., 2004, 205-250 y 26930, defendiendo la existencia de auténticas y válidas licencias, y DELGADO ECHEVERRÍA, J., 1997, 1480, considerándolas compraventas). Son prácticas aún vigentes en la residual distribución física de programas y, sobre todo, videojuegos. Los problemas de legalidad derivaban de si el adquirente conocía o no los términos de la licencia antes de comprar el programa, pues el precio 
por la caja que lo contenía se pagaba antes de poder acceder a su contenido y desprecintarlo. Tal eventualidad se compensaba con la posibilidad de devolución del paquete si el envoltorio interno que contenía el soporte con el programa no se había roto, lo que implicaba rechazo de la licencia $\mathrm{y}$, por lo tanto, al no haberse perfeccionado el contrato principal (la entrega del soporte era accesoria), procedía la devolución del precio por parte de la casa de software. En su versión en línea, las ahora generalizadas click-wrap licences, los problemas de celebración del contrato sin conocimiento de las condiciones desaparecen (lo que fortalece el argumento en pro de la existencia de este tipo contractual) al tener que aceptar las licencias propuestas por el fabricante en pantalla previa a los procesos de pago y descarga del programa, mediante el indicativo proceso de hacer click con el ratón en el botón "aceptar".

Los productores de software argumentaban varias razones para recurrir a la licencia de uso como alternativa a la compraventa: en primer lugar, como acabo de apuntar, dada la facilidad de copia y, sobre todo, la total fidelidad y funcionalidad de las copias privadas respecto de las originales, trataban de controlar el número de copias en el mercado (que no propiamente el uso que, realmente, nunca estuvo restringido), impidiendo que desde sus originales se crearan otras y, sobre todo, esas otras se transmitieran a terceros mientras quedaba en poder del copiante el ejemplar original adquirido. La facultad de decidir el número de ejemplares existentes en el mercado es propia del titular en ejercicio de sus derechos exclusivos de reproducción y distribución.

El formato digital, además, permitía definir tal número de forma independiente del número de soportes físicos: sobre un solo ejemplar podían licenciarse (autorizarse) varias copias o instalaciones del programa, lo que multiplicaba el número de copias comercializadas y permitía distinguir a los usuarios no por la adquisición del soporte, sino por el número de reproducciones autorizadas sobre el mismo. En este contexto, la licencia es el producto, por cuanto definía, mediante la delimitación del número de reproducciones autorizadas en ejercicio de los derechos de reproducción y distribución del titular, el objeto comercializado.

Por último, evitada la calificación de venta (que implicaba transmisión de propiedad) se impedía la operativa del agotamiento de su derecho de distribución, y permitía al titular prohibir al usuario la reventa o transferencia de la copia adquirida a un tercero, ilegalizando así los mercados de segunda mano. Las reventas eran un problema por cuanto podían quedar copias en poder de los cedentes, multiplicándose así el número de ejemplares en el mercado sin que el titular recibiera pago alguno por ellos.

El uso de licencias fue (relativamente) aceptado por los destinatarios usuarios de los 
programas de ordenador, dada la novedad del objeto, junto con una legislación ad hoc que impedía la realización de copias no autorizadas incluso para uso privado y las cesiones no autorizadas a terceros (art. $99 a$ y $c$ TRLPI): sabían (había varias advertencias en los paquetes y previas a las descargas) que aceptaban licencias, no adquirían ejemplares mediante compra. El problema de las licencias de uso no era su legalidad, pues sin duda eran contratos válidos, sino su forma de contratación, mediante las citadas prácticas de desprecintado de paquetes y soportes físicos. La normativa existente las tuvo en cuenta por el simple expediente de no prejuzgar la naturaleza de los contratos de distribución calificándolos de venta o alquiler (muy gráficamente, el primer inciso del segundo párrafo del art. $99 c$ TRLPI).

Con la llegada de internet y tecnologías que permiten el suficiente ancho de banda para la puesta a disposición de los programas vía su descarga en línea, los titulares trasladaron a este ámbito los contratos de licencia de uso con idénticas condiciones. Además, recibieron el respaldo de la Comisión Europea, para la cual solo había agotamiento, en su caso, cuando se distribuyeran por venta ejemplares físicos ${ }^{12}$; aunque la Directiva de Programas de Ordenador (DPO) ${ }^{13}$ no mencionaba explícitamente la comunicación pública del software, su suministro en línea (descargas) debía considerarse un servicio que, en cuanto forma de explotación, constituía ejercicio de este derecho, no del de distribución, y no operaba agotamiento alguno ${ }^{14}$.

\begin{abstract}
Aunque el Informe admitía que la dicción del art. 4 de la Directiva era tan amplia que podía llevar a interpretar que el art. 4 incluía en el derecho de distribución cualquier forma (no limitándose, por lo tanto, a la de copias tangibles), a la luz del posterior Tratado OMPI (1996) que preveía la modalidad de "puesta a disposición" como forma de comunicación pública y de los trabajos previos de la Propuesta de DDASI (que distinguían entre suministro en soporte y en línea como ejercicio de distintos derechos), la Comisión se mostraba partidaria de no interpretar el precepto
\end{abstract}

\footnotetext{
${ }^{12}$ En un primer momento, ésa fue la respuesta del Comisario Monti a la pregunta oral H-0436/95 de Arthur Newens, parlamentario europeo, el 11 de julio de 1995, Debates del PE (ed. es) no 466, pág. 189. Reiteró posteriormente su postura en el Informe de la Comisión al Consejo, al Parlamento Europeo y al Comité Económico y Social sobre la transposición y los efectos de la Directiva 91/250 sobre la protección jurídica de los programas de ordenador, 10.04.2000, COM (2000) 199 final, p. 18.
}

\footnotetext{
${ }^{13}$ Directiva 91/250/CEE del Consejo, de 14 de mayo de 1991, sobre la protección jurídica de programas de ordenador. Obsérvese que, trabajada desde finales de los ochenta, no contemplaba la explotación en línea por ser inviable en su época, tanto tecnológicamente como económicamente (no lo fue hasta mediadosfinales de los noventa). Fue derogada por su versión recodificada, la Directiva 2009/24/CE del Parlamento Europeo y del Consejo, de 23 de abril de 2009, sobre la protección jurídica de programas de ordenador (Versión codificada).
}

${ }^{14}$ Informe ..., cit., p. 18. 
tan ampliamente, de manera que no debía incluirse en él la puesta a disposición del público de obras a las que las personas pudieran acceder desde el lugar y en el momento que eligieran individualmente; en consecuencia, tratándose de un servicio, no operaría el agotamiento del derecho de exclusiva. En el caso UsedSoft, como se verá, la Comisión mantuvo esta interpretación, sosteniendo la existencia de un régimen unitario para todas las obras en formato digital. Obsérvese que, frente a la Directiva de 1991, el Informe es del año 2000 y la tecnología ya había hecho posible la explotación económicamente viable de estos formatos vía descarga de Internet.

Cuando la tecnología permite la distribución (rentable) de las obras tradicionales en formato digital (libros, música y películas), hubo intentos de recurrir también a las licencias como tipo negocial, pues los problemas de fácil copia y determinación del número de ejemplares en el mercado eran los mismos. No se impuso, sin embargo, pues la asimilación con la compra de los ejemplares en papel, soportes magnéticos y vinilos habituales sostuvo la pretendida calificación de venta, y no se acompañaba de documento de licencia alguno. Además, la existencia de reproducción necesaria para el uso era aquí más cuestionable, por lo que incluso desde el punto de vista jurídico cabía dudar de que hubiera algún tipo de cesión de derecho de reproducción aún limitado para dicho uso. El hecho de que algunos de los dispositivos en los que podían reproducirse (ordenadores) pudieran crear copias de los mismos y que, incluso, realizaran reproducciones efímeras durante su disfrute (carga en RAM, p. ej.) no implicaba que efectivamente hubiera de darse una tal reproducción técnicamente necesaria para su disfrute en sus dispositivos ad hoc (reproductores de CD y DVD, con la creación de copias que, aunque efímeras, permitieran al usuario la realización de otras). Y se contemplaba legalmente la excepción de copia privada, que no existía en el software.

Así las cosas, cabe destacar, por lo que ahora nos interesa, dos puntos de inflexión claves que explican la actual situación. En primer lugar, la adopción en 2001 de la Directiva de Derechos de Autor en la Sociedad de la Información, en la que el legislador plasma su visión, desde el punto de vista de la PI, sobre la explotación de las obras digitales: Su comercialización sobre soportes físicos constituye ejercicio del derecho de distribución que, si se realiza bajo la forma de compraventa, queda agotado y, por lo tanto, los adquirentes pueden revender los ejemplares adquiridos. Por el contrario, su puesta a disposición en línea, sin soporte tangible, constituye un servicio, que queda calificado de modalidad del derecho exclusivo de comunicación pública, en la que no opera el agotamiento, y así queda traspuesto en el TRLPI ${ }^{15}$. De dicha Directiva, sin embargo, se

${ }^{15}$ Cdo 28 (“[L]a protección de los derechos de autor, a efectos de la presente Directiva, incluye el derecho exclusivo a controlar la distribución de la obra incorporada en un soporte tangible") y Cdo 29 (“[E]1 
excluyeron los programas de ordenador ${ }^{16}$, cuyo régimen, a juicio del legislador europeo, ya había sido (completamente) armonizado; obsérvese, no obstante, que dicho régimen armonizado planteaba importantísimas dudas o lagunas, precisamente, en cuestión de distinción entre los derechos de distribución y comunicación pública, pudiendo interpretarse, incluso, que para los programas resultaran ser uno solo.

En segundo término, el pronunciamiento que sobre la naturaleza jurídica de la descarga de los programas de Internet realizó el TJUE en 2012, en el llamado caso UsedSoft ${ }^{17}$. Pudiendo haber quedado resuelta la cuestión de manera uniforme para todas las obras en formato digital, el problema es que, tanto en ese caso como en posteriores, el Tribunal dictaminó que se trata de una doctrina especial, no extensible al resto de obras electrónicas.

En el caso UsedSoft se discutió sobre la posibilidad de revender programas descargados en línea por parte de su adquirente. UsedSoft compraba licencias a usuarios que ya no las utilizaban, y las (re)vendía, de manera que los nuevos adquirentes podían acceder a los servidores de la casa de software (Oracle, en este caso, que fue la demandante) para descargarse los programas objeto de las mismas En realidad, lo que se compraba y revendía eran los números de licencia del programa, con los cuales el nuevo usuario adquirente acudía al sitio del proveedor y podía descargar y activar las copias descargadas. Esta argumentó (con cita del Cdo 29 y el art. 3.2 de la DDASI), en la línea de la Comisión y distintos gobiernos (entre ellos, el español; apdo 53), que no era posible, pues tal forma de suministro constituía un servicio en línea, respecto del cual no podía operar el agotamiento y, por lo tanto, habían de mantenerse las condiciones de la licencia que impedía cesiones por parte del usuario primer adquirente. Por lo tanto, el usuario original violaba los términos de la licencia, la actividad de UsedSoft era ilícita, y los sucesivos adquirentes no eran usuarios legítimos, ni a efectos contractuales ni legales.

problema del agotamiento no se plantea en el caso de los servicios, y en particular de los servicios en línea [...]. A diferencia del CD-ROM o CD-I, en los que la propiedad intelectual está incorporada a un soporte material, esto es, una mercancía, cada servicio en línea es, de hecho, un acto que debe quedar sujeto a autorización cuando así lo exijan los derechos de autor o derechos afines a los derechos de autor"); arts. 3 y 4 DDASI y 19 y $20.2 i$ TRLPI.

${ }^{16}$ Art. 1.2 a DDASI; finalmente, por lo tanto, no hubo el pronunciamiento o modificación de la DPO de 1991 que esperaba la Comisión en su citado Informe del año 2000.

${ }^{17}$ STJUE de 03 de julio de 2012, C-128/11, UsedSoft GmbH c. Oracle International Corp. 
Llegado el caso ante el Bundesgerichtshof (Tribunal Supremo alemán), este planteó al TJUE cuestión prejudicial sobre la interpretación de los conceptos de "distribución”, en relación con las descargas de internet, y “adquirente legítimo”, contenidos en los artículos 4.2 y 5 de la Directiva de Programas de Ordenador. El TJUE estimó que, dado que la DPO era normativa especial respecto de la general del Derecho de Autor contenida en la DDASI, y que ésta expresamente excluía a aquéllos de su ámbito de aplicación, no había propiamente comunicación pública (en su modalidad de puesta a disposición), sino un auténtico acto de distribución derivado de la calificación del contrato de licencia como verdadera compraventa. Efectivamente, dictaminó, cuando las llamadas licencias de uso suponen (1) conceder al usuario el derecho a utilizar una copia del programa; (2) de forma permanente; y (3) a cambio de un precio equivalente al valor económico de dicha copia, no estamos propiamente ante una licencia, aunque así la denomine el proveedor, sino un auténtico contrato de compraventa (apdos 42-46). Ello es sostenible tanto si la copia está sobre soporte tangible como si se trata de un archivo descargado de Internet, en virtud de la equivalencia funcional entre ambas: son esencialmente lo mismo y han de recibir el mismo trato (apdos 44, 49, 51, 52 y 61). Consecuencia de lo expuesto es que, habiendo venta de la copia de un programa (sobre un soporte, o suministrado en línea), procede el agotamiento del derecho de exclusiva (distribución) del titular sobre dicha copia, en aplicación del art. 4.2 DPO, y el adquirente inicial podrá revenderla. De lo contrario, se privaría de efecto útil a la regla del agotamiento, dice el TJUE, mediante el simple expediente de cambiar el nombre al contrato (apdo 49). Los sucesivos adquirentes de las "licencias" son también "usuarios legítimos" a los efectos de la normativa (apdos 73-85).

Obsérvese que toda esta argumentación se basa en la consideración de la normativa de programas como lex specialis respecto de la DDASI, habiendo manifestado en ambas el legislador voluntades diversas: en la primera, no se hizo distinción, dice el TJUE, entre distribución y comunicación pública, hablando, sin más, de formas de distribución pública (art. 4.2); en la segunda, sí, con distintos efectos.

La doctrina UsedSoft ha sido objeto de críticas por hacer una aplicación del Derecho atendiendo más a fines de política económica (apertura de mercados secundarios, de segunda mano) que jurídicos y no atender al proceso histórico de elaboración de las normas. 
La DPO de 2009 es solo una mera recodificación que no muestra la voluntad real de legislador de ese año, sino la de 1991, fecha de la Directiva original, que no tuvo en cuenta propiamente, como tal (diferenciada) la posibilidad de la descarga de programas de Internet por su propia época; la cuestión, realmente, no estaba abordada en la Directiva, y para cuando el legislador europeo se formó una voluntad sobre los servicios en línea, en 2001, debiera haberse hecho extensiva a aquélla (o bien, ser modificada en la misma línea), cosa que no hizo por la habitual conducta de "respetar" los ámbitos previamente armonizados, aun sin entrar a considerar la posible insuficiencia al respecto de la DPO de 1991.

Es posible (de hecho, es lógico y deseable) que, a estos efectos, los programas de ordenador y las demás obras en formato digital, deban tener el mismo régimen jurídico, pero no necesariamente el preconizado por el TJUE con criterios interpretativos dudosos por excesivos. Se necesita para ello un pronunciamiento expreso por parte del legislador aclarando la cuestión, por lo que la decisión del Tribunal peca de exceso sustituyendo la voluntad del legislador y creando Derecho ${ }^{18}$.

En realidad, las circunstancias que permiten la operativa del agotamiento quedan descritas de forma muy concreta en la sentencia, limitando algo sus efectos: cesión de uso de la copia del programa de forma indefinida temporalmente a cambio de un precio único equivalente al valor de dicha copia, con destrucción de copias en poder del cedente y sin posibilidad de fragmentación de las licencias ${ }^{19}$. Ello hace que, si no se da, por ejemplo, la cesión temporal indefinida, no estemos en presencia de una compraventa, sino un contrato distinto que impide la operativa del agotamiento ${ }^{20}$, por lo cual muchos titulares

\footnotetext{
${ }^{18}$ Algo, por otra parte, que es habitual en sede de PI, como ponen de manifiesto las sucesivas acotaciones jurisprudenciales del concepto de "comunicación pública", con desarrollos como el "público nuevo" o las presunciones de conocimiento o no de la ilicitud de los contenidos enlazados derivadas de la existencia o no de ánimo de lucro: entre otras, vid. SSTJUE 7 de diciembre de 2006, C-306/05 (caso SGAE); de 7 de marzo de 2013, C-607/11 (caso ITV Broadcasting); 13 de febrero de 2014, C-466/12 (caso Svensson); 8 de septiembre de 2016, C-160/15 (caso GSMedia, también conocido como Playboy); 14 de junio de 2017, C610/15 (caso The Pirate Bay); 7 de agosto de 2018, C-161/17 (caso Córdoba); 9 de marzo de 2021, C392/19 (caso SPK) igualmente, los Autos de 18 de marzo de 2010, C-136/09 (caso Organismos Sillogikis Dacherisis); y 21 de octubre de 2014, C348/13, (caso Bestwater).
}

${ }^{19}$ Es decir, no es posible revender por separado cada copia autorizada a partir de la única entregada, aunque
la "licencia" original permitiera la realización de más (varias instalaciones) a partir de ella: se "revende" la
misma licencia en iguales condiciones. Además, la copia revendida debe ser la adquirida, no una de
seguridad realizada, que solo sirve a los efectos del uso lícito del programa por parte del adquirente legítimo
(quien tiene la copia original), de manera que aunque la copia original se haya perdido, destruido o esté
dañada (en definitiva, no exista ya o sea inútil) el usuario primero no puede revender la copia de seguridad
que tenía derecho a realizar por ley (STJUE 12 de octubre de 2016 , C-166/15, Microsoft c. Ranks y
Vasilevičs, citando a UsedSoft en cuanto a los requisitos para que opere el agotamiento aun habiendo venta).

${ }^{20}$ Lo cual sucede, p. ej., con la primera sentencia del TS español que aplicó esta doctrina, de 1 de junio de
2016 (ECLI:ES:TS:2016:2594): en el caso de autos no se dan los requisitos establecidos para la
transferencia del derecho de propiedad de la copia del programa que agota el derecho del titular (definidos
previamente, conforme a UsedSoft, como "licencia de uso por tiempo indefinido, junto con la puesta a
disposición del programa en soporte material (CD- ROM o DVD) o inmaterial (a través de Internet)"), al 
cambiaron su modelo de negocio hacia suscripciones mensuales o anuales: el software as a service (SaaS) constituye una forma de alquiler (con descarga del programa en el dispositivo) o contrato de servicios, según configuraciones, a cambio de cesiones de uso temporales.

Así, p. ej., Adobe dejó de vender o ceder indefinidamente su conocido programa de retoque fotográfico Photoshop para licenciarlo en línea mediante suscripción que permite la descarga del programa y el uso de funcionalidades en red mediante números de licencia.

En muchos casos se trata de negocios reconducibles (si no se admitiera la categoría de las licencias de uso) al alquiler, pues el usuario obtiene (aún por descarga) una copia temporalmente utilizable, en tanto pague por el correspondiente período de uso, que queda inhabilitada (aunque esté en su poder) una vez terminado dicho período; otras veces, en cambio, es un auténtico contrato de servicios, en que el software ni siquiera tiene que ser descargado y el usuario accede, desde cualquier dispositivo, a un programa que se ejecuta (configura, mantiene, actualiza...) en los servidores ("nube") del proveedor (así, el novedoso Windows 365 de Microsoft, lanzado en 2021, o el más veterano Amazon Web Services, o AWS que ofrece algunos para consumidores finales, más allá de su oferta empresarial).

Como apunté, el TJUE construye la doctrina UsedSoft sobre el carácter de lex specialis de la normativa de tutela de los programas respecto de la general de Derecho de Autor. Por lo tanto, si la obra en cuestión no es un programa de ordenador sino de otra naturaleza (aunque contenga software), a la puesta a disposición de la misma le será de aplicación el general art. 3 DDASI y no el art. 4 DPO, tal cual lo interpreta el TJUE. Tras varias resoluciones nacionales en este sentido ${ }^{21}$, la cuestión fue finalmente abordada, y resuelta, por el propio TJUE en el caso Tom Kabinet ${ }^{22}$, en el sentido indicado: El suministro al público mediante descarga de un libro electrónico para su uso permanente ${ }^{23}$ está comprendido dentro del concepto de comunicación al público (modalidad "puesta a disposición del público de [las] obras [de los autores] de tal forma que cualquier persona pueda acceder a ellas desde el lugar y en el momento que elija”), en el sentido del artículo 3. DDASI. El TJUE basa sus conclusiones en el carácter especial de la normativa del software (apdo 54) y accesorio del programa respecto del contenido del libro electrónico

haber un límite temporal probado en la pactada licencia del programa; es por ello que el Tribunal reconduce el esquema del contrato de la compraventa al alquiler.

${ }^{21}$ En Alemania, las sentencias del Landgericht de Berlín de 21 de enero de 2014 (15 O 56/13) y 11 de marzo de 2014 (16 O 73/13), respecto de los videojuegos descargados de Internet bajo "licencia de uso" y el Landgericht de Bielefeld (LG Bielefeld, 05.03.2013, AZ 4 O 191/11, GRUR-Prax 2013, 207), para el suministro en línea de e-books, rechazaron la aplicación de la doctrina UsedSoft a estas otras obras digitales, dado su carácter especial para el software, considerando que en tales casos hay comunicación pública.

22 STJUE de 19 de diciembre de 2019, C-263/18, Nederlands Uitgeversverbond y Groep Algemene Uitgevers $c$. Tom Kabinet Internet BV y otros. Tom Kabinet prestaba, desde mediados de 2014, un servicio en línea consistente en un mercado virtual de libros electrónicos "de segunda mano". 
(apdo 59), así como en la falta de equivalencia funcional (que sí se da en las copias del software, sean distribuidas sobre un soporte físico o descargadas de Internet) entre un libro electrónico y un libro en papel (apdos 56 a 58); por último, aprecia en la descarga de un libro electrónico todos los requisitos típicos de una comunicación al público, ex art. 3 DDASI. ${ }^{24}$

La no extensión de la doctrina UsedSoft al resto de obras digitales ha sido duramente criticada por algún sector de la doctrina, que no encuentra justificación para mantener una tal diferencia de trato y aboga por la extensión a todas las obras en formato digital de la citada doctrina, de manera que sea posible la reventa de las copias adquiridas, sean sobre soporte, sean obtenidas mediante descarga (DELGADO GARCÍA-POMAREDA, J. 2020). Por mi parte, creo efectivamente que hay esa equivalencia funcional, incluso en libros electrónicos y, por lo tanto, es difícil justificar hoy en día una diferencia de trato entre las obras digitales sobre soporte físico y las descargadas, así como entre los programas y el resto de formatos digitales, pero, en el actual estado normativo, no es posible aceptar esa extensión de la doctrina UsedSoft al resto de las obras en formato electrónico.

\begin{abstract}
Ni siquiera a otras de más dudosa naturaleza, como los videojuegos, pues estos tampoco son solo programas de ordenador, sino obras complejas distintas de su software (STJUE de 23 de enero de 2014, C-355/12, Nintendo Co. Ltd y otros contra PC Box Srl y 9Net Srl); es por ello que no creo acertada, en este concreto punto, la decisión del Tribunal de Grande Instance de París de 17 de septiembre de 2019, anulando las cláusulas de Valve (propietaria de la plataforma de videojuegos Steam) que prohíben la reventa de sus videojuegos por considerar que hay transmisión de propiedad de los juegos a perpetuidad aunque sea a través de descarga (se llegan a anular hasta 14 cláusulas del contrato de Valve). Para el tribunal francés, "[e]nfin, l'"abonnement" à la "souscription" (d'un jeu) effectué par l'utilisateur, dont il est fait état dans les conclusions de la société VALVE [...] consiste en réalité en un achat, le jeu étant mis à la disposition dudit utilisateur pour une durée illimitée. Il ne peut donc s'agir d'un "abonnement" - au sens usuel du terme - mais de la vente d'un exemplaire d'un jeu vidéo, réalisé moyennant un prix déterminé à l'avance et
\end{abstract}

\footnotetext{
${ }^{24}$ En cambio, el TJUE sí ha mantenido la equivalencia entre el libro tradicional y el electrónico descargado desde el servidor de una biblioteca a efectos de la Directiva 2006/115 en lo relativo solo al préstamo (STJUE de 10 de noviembre de 2016, C-174/15, Vereniging Openbare Bibliotheken c. Stichting Leenrecht). El TJUE diferencia entre el "alquiler", en el que no sería posible esa equiparación, y el "préstamo", en el que sí, pues tienen en la Directiva 2006/115 diferentes regímenes (art. 2, son definidos de distinta manera) y, por lo que ahora interesa, una excepción, la del art. 6, que afecta solo al préstamo, no al alquiler; el legislador ha querido, por lo tanto, darles diferente tratamiento. Por ello "dada la importancia de los préstamos públicos de libros digitales, y a fin de salvaguardar tanto el efecto útil de la excepción de préstamo público prevista en el artículo 6, apartado 1, de la Directiva 2006/115 (...) como la contribución de ésta a la promoción cultural" (apdo. 51); por ello, "se debe considerar que esa operación presenta características comparables en sustancia a las de los préstamos de obras impresas, a la luz en especial de las condiciones enunciadas en el artículo 2, apartado 1, letra b), de la Directiva 2006/115, toda vez que la limitación de las posibilidades de descarga simultánea a una sola copia implica que la capacidad de préstamo de la biblioteca interesada no excede de la que tiene si se trata de una obra impresa, y ese préstamo sólo se realiza por un tiempo limitado" (apdo 53).
} 
versé en une seule fois par l'utilisateur". Es una inaceptable traslación de la doctrina UsedSoft a una obra, videojuego, que no es propiamente un programa de ordenador, sino otra distinta, a cuyo suministro por Internet hay que aplicar la DDASI.

El TJUE, siendo excesivo en UsedSoft es, al menos, coherente con las bases de su argumentación y sus necesarias consecuencias: "esta asimilación de las copias materiales e inmateriales de obras protegidas a efectos de las disposiciones pertinentes de la Directiva 2001/29 no fue deseada por el legislador de la Unión al adoptar dicha Directiva. En efecto [...], se desprende de los trabajos preparatorios de la propia Directiva que se quiso establecer una clara distinción entre la distribución electrónica y la distribución material de contenidos protegidos".

\begin{abstract}
Obsérvense las diferencias y semejanzas con la aproximación judicial estadounidense, donde también se ha abordado el mismo problema. En el caso Vernor (Vernor v. Autodesk, 621 F.3d 110, (9th Cir. 2010) el usuario pretendía revender por eBay (subastándola) una copia del software amparándose en la doctrina de la first sale. El Tribunal estimó que ello sería posible si hubiera habido una compraventa de la copia originalmente transferida a dicho usuario por la casa de software, pero consideró que el contrato concluido era de licencia, pues se imponían significativas restricciones de uso (Autodesk retenía la propiedad de Autocad, prohibía su transferencia o alquiler sin su consentimiento por escrito, y nunca más allá del hemisferio occidental); lo relevante para lo que nos ocupa es que el propio Tribunal aprecia que hay sólidos argumentos también a favor de que se permita la reventa, mas, para su admisión, apunta expresamente, debería haber un cambio legislativo. En el conocido caso ReDigi (Capitol Records LLC v. ReDigi Inc. (S.D.N.Y. Mar. 30, 2013), ReDigi pretendía revender contenidos de iTunes mediante un software que los transfería al comprador borrándolos del ordenador del vendedor; el Juez dictaminó que no opera la doctrina de la first sale, al no distribuirse objetos materiales, sino digitales, reproducciones de códigos sujetos a copyright que se encuentran en los servidores del proveedor y en los discos duros de los usuarios. Así pues, la aproximación estadounidense es similar, pero más coherente, al dar un trato único a software y otras obras digitales distribuidas en línea, a la espera de un pronunciamiento legislativo expreso.
\end{abstract}

En definitiva, también en sede de Derecho de propiedad intelectual se da una pluralidad de contratos de explotación y regímenes sobre suministros de bienes que son sustancialmente idénticos estén o no sobre un soporte físico, con el agravante de diferenciar entre obras en un mismo formato.

\title{
4. Propuesta de unificación de los tipos contractuales en el suministro de contenidos digitales
}

Se afirma con cierta frecuencia (y así parece desprenderse de los Cdos de las Directivas citadas hasta el momento) que las categorías clásicas del Derecho contractual no siempre encajan bien (MARTÍNEZ VELENCOSO, L. M. y SANCHO LÓPEZ, M., 2018, 4) en 
orden a calificar el suministro de contenidos y servicios digitales. Ello conduce a su consideración como contratos sui generis o tertius genus, lo cual es, quizá, una solución un tanto simple y que tampoco aclara nada: el régimen jurídico de un contrato atípico parte de la libertad contractual (art. 1255 CC) para, en lo no previsto, aplicar analógicamente la regulación de aquel o aquellos otros que le sean más próximos; y ello, respetando siempre la normativa imperativa de aplicación (p. ej., la de protección de los consumidores o de los titulares de derechos de exclusiva).

Lo cierto es que el legislador (europeo) podría tipificar tales contratos de suministro de contenidos y servicios digitales, dándoles una definición y un régimen básico, aunque se antoja difícil, dada la diversidad de objetos y prestaciones, que conduciría nuevamente a la aplicación parcial (por remisión o por analogía) de los tipos existentes; a ello se suman las complejidades técnicas y las diferencias entre las tradiciones jurídicas de los distintos Estados miembros. Además, cabe señalar también que realmente está regulando tal suministro de forma amplia, aun prescindiendo de su definición y/o calificación, centrándose en la protección de los distintos sujetos implicados (consumidores y prestadores de servicios a través de las plataformas ${ }^{25}$ ).

Procede, por lo tanto, y aun con las limitaciones de espacio del presente estudio, concluir con unas breves consideraciones sobre las posibilidades de reconducción de las distintas modalidades de suministro de contenidos y servicios digitales a tipos existentes, con unos mínimos (aunque trascendentes) cambios legislativos en sede de propiedad intelectual.

\subsection{Sobre los contratos onerosos de prestación única}

Sobre la base de la doctrina sentada por el TJUE en UsedSoft, la DPO y la DDASI es posible sostener fundadamente que el suministro de obras protegidas en formato digital (y, por extensión, de contenidos digitales no protegidos) fijadas a un soporte material, por cuya virtud se concede al usuario el derecho a utilizar tal copia de forma permanente a cambio de un precio equivalente al valor económico de la misma, constituye, en ejercicio del derecho de distribución del titular de la obra, una auténtica compraventa.

\footnotetext{
${ }^{25}$ Reglamento (UE) 2019/1150 del Parlamento Europeo y del Consejo, de 20 de junio de 2019, sobre el fomento de la equidad y la transparencia para los usuarios profesionales de servicios de intermediación en línea.
} 
Podría también extenderse este régimen a todo tipo de obras en formato digital puestas a disposición de los consumidores para su descarga en línea, con una expresa modificación de la DDASI en el sentido en que el TJUE interpreta la DPO, sobre la base de la equivalencia funcional en el objeto contractual: la copia sobre soporte tangible y el archivo descargado de la red. Para ello sería necesario, como reiteradamente vengo apuntando, una decisión del legislador en orden a considerar la descarga no como un acto de comunicación pública, sino de distribución, sobre la base de la consideración del ejemplar disociado del soporte físico o, de otra forma, que dicho soporte puede ser tanto físico como inmaterial. En cualquier caso, la copia de la obra en formato digital sería considerada mercancía, bien o producto a todos los efectos. Ello implicaría la modificación de los citados Cdos 28 y 29 de la DDASI, con la consiguiente afectación del art. 4 que recoge, aún sin definirlo, el derecho de distribución. En nuestro TRLPI, sería expresamente necesaria la modificación del art. 19, en el siguiente sentido (en cursivas el añadido a lo actualmente vigente): “[S]e entiende por distribución la puesta a disposición del público del original o de las copias de la obra, en un soporte tangible $o$ intangible, mediante su venta, alquiler, préstamo o de cualquier otra forma”.

\begin{abstract}
Puede introducirse cualquier variante, del tipo "soporte tangible o por su descarga en línea, mediante...". Opto por la referencia al soporte "intangible" (inmaterial, o similar) porque la propia normativa de propiedad intelectual ya conoce este concepto: el art. 10 TRLPI se refiere a las creaciones originales como objeto de la norma que se expresen "por cualquier medio o soporte, tangible o intangible, actualmente conocido o que se invente en el futuro". La (in)tangibilidad puede predicarte tanto del medio como del soporte, de manera que una obra musical, teatral o pantomima son tradicionalmente expresadas por un medio "intangible", pero también puede serlo, en la actual sociedad y tecnología, el soporte-formato digital. De hecho, se habla en ocasiones hasta de "soporte inmaterial" (vid. la citada STS de 1 de junio de 2016, FJ 3), lo cual puede incluir tanto el propio archivo electrónico y su formato como, en una concepción más amplia, la electricidad o los estados de la materia en que consisten los propios bits que codifican la obra o contenido.
\end{abstract}

De los arts. 3 DDASI y 20 TRLPI quedaría excluida esta descarga como prestación única si se diera en el marco de un servicio en ejercicio del derecho de comunicación pública.

Lo cierto es que tal equivalencia es innegable (aun con algunos problemas, como apunta CASTILLO PARRILLA, J. A., 2018, 182) y una decisión de política legislativa en este sentido no resultaría particularmente contraria a los intereses de la industria de creación de contenidos y los titulares de derechos de autor. La cuantificación del objeto contractual (el número de copias que el consumidor-usuario puede realizar a partir del ejemplar 
adquirido o descargado) puede hacerse de la misma manera en ambos canales de distribución, de manera que, a través del suministro de un solo ejemplar, físico o inmaterial, se autoricen dos o más copias lícitas. Toda otra posible copia hecha por el consumidor (destinatario de la obra) al margen de dicha autorización sería ilegal por vulnerar el derecho exclusivo de reproducción del titular y, como tal, perseguible civil y, en su caso, penalmente (si se hace con ánimo de lucro mediante su reventa).

\begin{abstract}
No creo, sin embargo, que los legisladores, europeo y nacional, tengan una clara (y única) postura al respecto, pues las tensiones desde los extremos son importantes. En el Report on the responses to the Public Consultation on the Review of the EU Copyright Rules, de la Dirección General de Mercado Interior y Servicios, julio 2014 se preguntó, entre otras cuestiones, sobre la reventa de contenidos digitales (preguntas 13 y 14, pp. 20-22). Los titulares de derechos se mostraron contrarios a la extensión del agotamiento, pues creían que favorecería la piratería y dañaría el mercado primario, amén de las dificultades para controlar la destrucción de la copia en poder del revendedor; los usuarios, por su parte, consideraban que deben tratarse como cualquier otro bien material. Los Estados, en su mayoría, no se pronunciaron de forma definitiva, aunque parecían partidarios de mantener el statu quo, pues no sabían si permitir el agotamiento redundaría en beneficio (mayor oferta) o perjuicio (mayores precios de los originales) de los propios consumidores. En la fracasada Propuesta de Reglamento del Parlamento Europeo y del Consejo relativo a una normativa común de compraventa europea, COM (2011) 635 final, de 11 de octubre (abreviada CESL por sus siglas en inglés: Common European Sales Law) no se incluía propiamente dentro de la compraventa de bienes a los contenidos digitales (bienes y contenidos digitales eran objetos distintos: art. $2 h$ y $2 j$ ), aunque el art. 5 señalaba que se podía "recurrir a la aplicación de la normativa común de compraventa para regular" tanto los contratos de compraventa como los de suministro de contenidos digitales (con o sin soporte) y los contratos de servicios relacionados. El Anexo de la Propuesta desarrollaba las reglas comunes, sometiendo al "proveedor de contenidos digitales" a las mismas normas que al vendedor, (p. ej., en cuanto a conformidad). Es decir, seguía habiendo dudas sobre la auténtica naturaleza del suministro de contenidos digitales, pero se optaba por unificar regímenes sobre la base de la compraventa (tradicional). La decisión de unificar estos regímenes (SPINDLER, G., 2012, 458) se basaba en un previo estudio de la Universidad de Amsterdam (disponible en https://hdl.handle.net/11245/1.345662), que concluía que, a pesar de las posiciones de la industria, el consumidor debía ver garantizada su posición y expectativas respecto del contenido digital "based on previous experiences with digital content or similar experiences with traditional, tangible goods, which may resemble the digital content now purchased, or on more abstract notions such as public order and the protection of privacy or fundamental rights"; por lo tanto, las normas de conformidad podrían aplicarse también a estos contenidos con independencia de la clasificación contractual. GARROTE FERNÁNDEZ-DÍEZ, I. $(2013,759)$ señalaba que, por lo tanto, era una decisión deliberada, aunque dudaba, a pesar de dicho estudio, de que fuera reflexionada. En todo caso, sí parece que se ha sostenido en el tiempo la asimilación, en el ámbito contractual de consumo, hasta la actual DCSD y la reforma de la DDC por la Directiva 2019/2161; no ha sido así, sin embargo, en sede de PI, sin cambio alguno y donde, a mi juicio, los legisladores simplemente están esperando a ver cómo evoluciona y/o resuelve la cuestión el propio mercado o los titulares crean nuevos modelos de explotación.
\end{abstract}

Cabría, además, otra línea de modificación normativa: la introducción en el derecho exclusivo de reproducción de una completa excepción de reproducción a efectos de uso ${ }^{26}$,

\footnotetext{
${ }^{26}$ En las normas vigentes, el legislador optó por un concepto jurídico muy amplio de "reproducción" para garantizar la posición de los titulares, incluyendo las de todo tipo, incluso fijaciones indirectas y provisionales (arts. 2 DDASI y 18 TRLPI), por lo que, salvo contemplación de excepciones expresas (como
} 
a la manera de lo que ocurre con las reproducciones transitorias, accesorias y sin significación económica que tienen necesariamente lugar durante la transmisión en línea de la obra (arts. 5 DDASI y 31.1 TRLPI). Realmente, y como señala el propio art. 5 DDASI, la reproducción a efectos de uso es, en el actual estado de la técnica, necesaria y en nada perjudica a la exclusiva del titular. Incluso en el ámbito de los programas de ordenador, donde el legislador parece llegar al absurdo de permitir al titular prohibir incluso el uso para el cual el programa ha sido adquirido (arts. 99.1 y 100.1 TRLPI), la eficacia del contrato obliga a permitir tal reproducción pues de lo contrario quedaría sin objeto ni causa. Siendo un acto obligado, puede quedar excluido de la exclusiva del titular, de manera que, como sucede con la comercialización de un tradicional libro en papel o un vinilo, no se afectarían sus derechos. Ello hace más intuitivamente reconducible el régimen de suministro, tanto sobre soporte como mediante descarga, al del comercio tradicional de ejemplares físicos de obras protegidas. Y, como se ha dicho, los derechos de reproducción del titular quedarían incólumes y garantizados normativamente frente a toda posible copia que suponga reproducción no necesaria o autorizada.

En virtud de todo lo expuesto, si se implementaran dichas modificaciones normativas que unificaran el régimen para todas las obras en formato digital, celebrado un contrato oneroso que permita el uso indefinido del contenido digital fijado en un soporte material o descargado en línea será calificado de compraventa o permuta, y (1) se transferirá la propiedad del ejemplar (soporte, en su caso, como accesorio, y la copia de la obra protegida a él fijada o descargada, como bien principal transferido y que podrá disfrutar en número según se le autorice: una, dos o más copias); (2) operará el agotamiento de la exclusiva del titular, pudiendo el usuario revender su ejemplar siempre que lo haga en las mismas condiciones en que se le suministró (sin fragmentación del objeto del contrato, en caso de que sobre el ejemplar entregado se le permitieran hacer más copias) y no quede en su poder ninguna copia; y (3) se aplicará a dicho contrato de suministro todo lo previsto en las normas de protección de consumidores y usuarios en lo relativo a la forma de la celebración del contrato a distancia y desistimiento (en su caso), la información a suministrar y la conformidad del contenido digital vendido.

la del art. 31.1 TRLPI) siempre que hay alguna fijación hay “reproducción” sujeta a la exclusiva del titular. 
No empece a la posible calificación de compraventa que esta obligue o no a transmitir propiedad. En nuestro Derecho tradicional, la compraventa obliga a la entrega de la cosa, no a la transmisión de su propiedad, a pesar de lo cual, en prácticamente todos los casos, esta es una obligación del vendedor ${ }^{27}$.

\begin{abstract}
Aunque en nuestro Derecho está clara la naturaleza obligacional de la compraventa (arts. 1445, 1461, 1462 del Código Civil) y que para la adquisición de la propiedad rige (base 20 de la Ley de Bases de 1 de mayo de 1888 conforme a la cual se redactó el Código, art. 1095 CC) la doctrina del título (contrato) y modo (entrega), se ha cuestionado tradicionalmente si el vendedor queda obligado a transmitir la propiedad de la cosa, pues el art. 1445 CC no lo establece así expresamente. Frente a quienes, con fundamento en la literalidad del precepto y el antecedente del Proyecto de 1851, lo niegan, cabe sostener que sí, en una más acertada interpretación conforme con la finalidad del contrato, ex art. 1258, conforme a los usos, dado que es la pretensión y finalidad económica habitual tanto de las partes como del contrato en sí (explica DíEZ-PICAZO, L., 2010, 57-59). Salvo muy residuales excepciones, la compraventa es el tipo para la mayor transmisión posible de derechos, que es lo que las partes buscan, de ahí que, aun cuando nada se diga ni conste legalmente como causa de la misma, la transmisión de la propiedad es consecuencia de la misma en la inmensa mayoría de los casos, aunque sea con la entrega posterior del bien; desde luego, lo es en el ámbito de consumo, ahora regulado, pero incluso con anterioridad, en base a las consideraciones hechas. En el caso de las licencias de programas de ordenador y otros contenidos digitales, precisamente, el licenciante trataba mediante su presentación en los años ochenta y noventa, como se ha explicado, de destruir esa apariencia creada en el comercio habitual y las expectativas del usuario contraparte al adquirir el soporte físico.
\end{abstract}

Específicamente, en la normativa de consumo, se ha definido la venta como el contrato por el cual el suministrador transmite o se obliga a transmitir la propiedad de los bienes (art. 59 bis $1 f$ TRLGDCU); pueden concurrir, además, prestaciones de servicios, de forma accesoria (p. ej., mantenimiento o actualización de los contenidos digitales vendidos). Más que alterar el régimen tradicional, se hace claro en un ámbito en el que el consumidor espera, precisamente, que se le entregue la propiedad del bien adquirido, aunque sea un contenido digital, con todo lo que ello implica. En el actual estado normativo, la antigua pretensión de los titulares de derechos de propiedad intelectual de no transmitir propiedad para garantizar sus derechos resulta innecesaria, una vez sus derechos de exclusiva quedan tutelados respecto de cualquier obra en formato digital y resulta clara la absoluta ilicitud de toda copia no autorizada (p. ej., la que quedara en poder del usuario transmitente), por lo que, dadas las expectativas del consumidor contraparte, resulta muy difícil sostener la existencia de un contrato diferente si no hay limitación temporal del uso o disfrute de la obra protegida.

\footnotetext{
${ }^{27}$ Para la STS de 1 de diciembre de 1986 (ECLI:ES:TS:1986:7802), "la venta es, por definición, un acto de enajenación, puesto que su finalidad es la traslativa del dominio, que se consuma mediante la entrega de la cosa".
} 


\begin{abstract}
No es obstáculo tampoco el Derecho de autor para la existencia de compraventa sobre derechos de exclusiva. Si bien el TRLPI y demás normativa de propiedad intelectual diseñan contratos que no son propiamente de venta (son cesiones limitadas temporal y territorialmente, para proteger al autor frente a la industria), y dejando al margen los derechos morales (irrenunciables), la venta no se excluye en dichos textos ni en los arts. 428 y $429 \mathrm{CC}$, que siguen vigentes y reconocen tanto la libertad del autor para la explotación de su obra a voluntad como el carácter supletorio del CC en lo no previsto por el TRLPI.
\end{abstract}

En este sentido, si el derecho concedido sobre el ejemplar físico o descargado en línea a cambio del precio es solo temporal, el contrato (aun llamado "licencia") será calificable de arrendamiento (alquiler), no se transferirá propiedad alguna y no operará el agotamiento del derecho de distribución del titular, no quedando facultado el consumidorarrendatario para transferir su derecho de uso sin autorización del titular-suministrador. No obstante, a dicho contrato le será de aplicación la normativa de protección del consumidor, pues en todo caso ha de garantizarse la conformidad, entendida aquí como uso o disfrute pacífico del contenido cedido durante el tiempo de vigencia del contrato. Al finalizar, el consumidor-arrendatario tendrá que devolver, destruir o, más probablemente, soportar sin más la inutilidad sobrevenida de la copia en su poder.

En presencia de contratos gratuitos (software libre y gratuito, música, texto o vídeos de libre acceso sin contraprestación alguna, ni siquiera datos personales), reconducibles al esquema de las donaciones (cesiones de derechos indefinidas) o préstamos (cesiones temporales), el consumidor podrá hacer uso (disfrutar) del contenido digital que le ha sido entregado, se ha descargado o se ha puesto a su disposición en los términos impuestos por el titular (normalmente, respeto (cita) de la autoría, sin más, pero caben otras posibilidades: transformación o no de la obra, reutilización con fines comerciales o no ,etc.); ello supone, si hay transferencia de propiedad, agotamiento del derecho de distribución sobre dicha copia, que el consumidor podrá transferir libremente, aunque no podrá beneficiarse del régimen protector establecido en la normativa de consumo en lo relativo a la información, conformidad y, en su caso, desistimiento, que expresamente excluye a este tipo de contratos, en cuanto realmente sean tales (gratuitos, es decir, que tampoco escondan una contraprestación en forma de cesión de datos personales opaca para el consumidor, sin perjuicio de lo ilícito que ello sea conforme a su respectiva normativa; arts. 3.1 y $3.5 f$ DCSD y 59.4 TRLGDCU). 


\title{
4.2. Sobre los contratos onerosos temporales de prestación continuada o sucesiva
}

Los servicios digitales constituyen una noción intuitiva pero de difícil descripción, dada su gran variedad; en cuanto servicios de la Sociedad de la Información, pueden, además, revestir diferente naturaleza (compraventas, alquileres, contratos de obra, etc.), incluyendo, por supuesto, la de auténticos contratos de servicios, en el sentido técnico jurídico de la expresión: contratos de prestaciones continuada o sucesivas (de hacer, esencialmente, pero también de dar) a cargo del proveedor a cambio de un precio que paga el comitente (en este caso, consumidor), durante el tiempo estipulado.

\begin{abstract}
El contrato ("arrendamiento", en la terminología clásica del art. 1544 CC) de servicios tiene, por definición, una duración temporal determinada (no puede ser vitalicio, art. 1583), si bien esta puede ser concreta o por períodos renovables, por lo que cabe su configuración como tendencialmente indefinido. En todo caso, siempre puede ser objeto de denuncia por parte del consumidor (art. 62 TRLGDCU). En su práctica totalidad, se trata de contratos onerosos, en los que el usuario paga un precio en dinero por período de disfrute $o$, bajo la apariencia de una aparente gratuidad (en cuanto no hay pago en dinero), se ceden datos de carácter personal, lo que lleva también a la aplicación de la normativa de protección del consumidor (y, por supuesto, a la de protección de datos y la necesidad de dar consentimiento expreso al respecto).
\end{abstract}

El disfrute de los contenidos ofertados solo durante el tiempo de suscripción del servicio es, en este caso, elemento esencial del contrato, conocido suficientemente por el consumidor medio que actúa de buena fe y acorde con los usos (art. $1258 \mathrm{CC}$ ) lo que excluye toda posible consideración de cesión perpetua de derechos y, por lo tanto, de compraventa.

Por lo que ahora interesa, en su relación con la PI, consisten fundamentalmente en el suministro (puesta a disposición en línea) de contenidos digitales a petición del destinatario, mientras dure el contrato, de entre el catálogo que ofrezca el proveedor y en las formas que este permita: vídeo y/o audio bajo demanda, descarga, fuera de línea, etc. Normalmente, como valor añadido o prestaciones de tipo accesorio, se ofrecen índices y buscadores de contenido, valoración y metainformación (datos añadidos sobre el contenido objeto del disfrute: biografía del director o músico, actores que intervienen en una escena, instrumentos que suenan, letra de la canción, y su traducción), contenidos relacionados en función de los disfrutados previamente, alertas de puestas a disposición de otros nuevos según preferencias, espacio de almacenamiento (de contenidos propios del usuario o descargados del prestador), etc. En servicios de intercambio y redes sociales, también la subida de contenidos propios que los usuarios (convertidos en consumidores 
activos, prousuarios o auténticos autores creadores), comparten con terceros.

Por supuesto, en el marco de la prestación del servicio digital pueden existir concretas obligaciones de dar y de resultado: así, la descarga de un software que permita la prestación en sí del servicio, o un archivo concreto de audio o vídeo para el disfrute de un contenido fuera de línea (pero dentro del plazo de ejecución del contrato).

Mediante la prestación de estos servicios, el titular de las obras protegidas ejercita su derecho de comunicación pública, bien de forma directa (es el proveedor del servicio), bien indirecta (mediante cesiones de tal derecho al prestador del servicio, para su explotación en exclusiva o no por comunicación pública por parte de este). En tales casos no hay previa distribución de ejemplares (ni siquiera inmateriales, al menos a efectos jurídicos) para su disfrute indefinido, no opera el agotamiento de su exclusiva, que mantiene (y, por lo tanto, puede lícitamente prohibir al usuario la transferencia de las copias que este tenga en su poder como resultado del uso del servicio), y el disfrute del servicio ha de hacerse en las condiciones que establezca el prestador. Entre otras consecuencias, ello permite impedir el juego de la excepción de copia privada, que no opera aquí en beneficio del usuario (art. 31.3 a TRLPI). En tales casos podría plantearse la existencia de arrendamientos (a la manera, p. ej., del alquiler de una película en un videoclub) pero no se trata de contratos aislados (aun vinculados por una suscripción), sino de concretas ejecuciones del servicio tal cual fue definido por las partes (en realidad, el ofertado por el suministrador y aceptado por el usuario). De hecho, puede ser causa de suspensión (imposibilidad de disfrute temporal del servicio, o de las copias o en los dispositivos excedidos) o resolución del contrato de servicios en sí el incumplimiento de las condiciones del servicio respecto de tales prestaciones únicas, como la violación de los derechos de propiedad intelectual por realización de copias no permitidas u otras causas vinculadas a una posible consideración intuitu personae del lado del usuario contratante, tales como que este permita el disfrute de tales contenidos por terceros no autorizados, mediante cesión de sus claves fuera del ámbito consentido, generalmente el familiar; o se exceda en el número de dispositivos (o tipo de hardware) desde los que es posible acceder. 


\section{Conclusiones}

En el actual estado normativo, no existe un régimen jurídico contractual uniforme para la explotación de los derechos de propiedad intelectual sobre obras en formato digital en el mercado de consumo. El ejercicio del derecho de distribución se canaliza principalmente a través de contratos de compraventa, cuando se comercializan ejemplares físicos otorgando derechos temporalmente indefinidos sobre las copias que contienen a cambio de un precio único y equivalente a su valor. No obstante, existen otras formas, como el alquiler (p. ej., en el mercado de videojuegos), o la donación o préstamo (gratuitos).

Cuando la obra es suministrada sin soporte, mediante su descarga de Internet, se ejercita un derecho distinto, el de comunicación pública, a través de un contrato de servicios, salvo que la obra sea un programa de ordenador, en cuyo caso, merced a la (discutible) interpretación del TJUE se mantiene la distribución a través de una auténtica venta. Para el resto de contenidos/servicios digitales no sujetos a propiedad intelectual no existe interferencia de normativas, y son suministrados generalmente en forma de compraventa, donación o como prestaciones continuas o puntuales dentro de un contrato de servicios.

De lege ferenda, es deseable una aclaración del panorama contractual, previo obligado pronunciamiento por parte del legislador (europeo) en sede de propiedad intelectual, que permita calificar la inmensa mayoría de suministros puntuales onerosos de contenidos y servicios digitales como compraventas o permutas (cuando la contraprestación sean datos personales). Ello puede lograrse mediante algunas modificaciones que, aun siendo puntuales suponen un cambio de paradigma en la protección de los derechos de propiedad intelectual: redefiniendo el derecho de distribución para incluir en él la explotación comercial de los formatos digitales (obras en soportes no tangibles) y excluyendo del derecho de reproducción las provisionales y accesorias que sean estrictamente necesarias desde el punto de vista técnico para el disfrute de tales formatos.

\section{Referencias bibliográficas}

APARICIO VAQUERO, J. P. (2004), Licencias de uso no personalizadas de programas de ordenador. Shrink-wrap, click-wrap y otras formas de distribución de software, Granada, Comares. 
APARICIO VAQUERO, J. P. (2019), "El valor económico de un derecho fundamental: la monetización de los datos personales”, en BAUZA REILLY, M. (dir), El Derecho de las TIC en Iberoamérica, Montevideo, La Ley Uruguay, pp. 1027-1035.

CÁMARA LAPUENTE, S. (2014), "La nueva protección del consumidor de contenidos digitales tras la Ley 3/2014, de 27 de marzo", Revista CESCO de Derecho de Consumo, 11, 2014, pp. 79-167.

CASTILLO PARRILLA, J. A. (2018), Bienes digitales. Una necesidad europea, Madrid, Dykinson.

CASTILLO PARRILLA, J. A. (2021), Los datos personales como contraprestación en la reforma del TRLGDCU y las tensiones normativas entre la economía de los datos y la interpretación garantista del RGPD. La Ley Mercantil, nº 82 (jul-ago), La Ley 8528/2021.

DELGADO ECHEVERRÍA, J. (1997), “Comentarios al Título VII y a los arts. 95-104”, en BERCOVITZ, R. (coord.) Comentarios a la Ley de Propiedad Intelectual, 2. ${ }^{\mathrm{a}}$ ed., Madrid, Tecnos, pp. 1341-1520.

DELGADO GARCÍA-POMAREDA, J. (2020), “Oportunidades perdidas, reventa digital y agotamiento online: De UsedSoft a Tom Kabinet", Pe.i. Revista de Propiedad Intelectual, 64, enero-abril, pp. 69-117.

DÍEZ-PICAZO, L. (2010), Fundamentos del Derecho Civil Patrimonial IV. Las particulares relaciones obligatorias, Madrid, Thomson Reuters.

ESPÍN ALBA, I. (2020), “Contrato de suministro de contenidos y servicios digitales en la Directiva 2019/770/UE. Datos, consumidores y "prosumidores" en el Mercado Único Digital", Revista de Derecho Privado, 6, pp. 3-38.

FUENTESECA DEGENEFFE, C. (2018), "Mercado Único Digital: algunos aspectos de la regulación del suministro de contenidos digitales", Revista de Derecho Civil, 2 (abriljunio, 2018), pp. 107-148. 
GARCÍA HERRERA, V. (2020), "El pago con datos personales. Incoherencias legislativas derivadas de la configuración de los datos como posible "contraprestación" en el suministro de contenidos y servicios digitales", Actualidad Civil, 1, La Ley $672 / 2020$.

GARROTE FERNÁNDEZ-DÍEZ, I. (2013), “Compraventa y suministro de contenidos digitales en la Directiva 83/2011 y CESL”, en CARRASCO PERERA, Á. (dir.), Tratado de la Compraventa, Cizur Menor, Thomson Reuters Aranzadi, pp. 753-763.

GRIMALT SERVERA, P. (2013), “Compraventa y suministro: tracto sucesivo y régimen resolutorio", en CARRASCO PERERA, Á. (dir.), Tratado de la Compraventa, Cizur Menor, Thomson Reuters Aranzadi, pp. 129-139.

MARTÍNEZ VELENCOSO, L. M. y SANCHO LÓPEZ, M. (2018), "El nuevo concepto de onerosidad en el mercado digital. ¿Realmente es gratis la App?”, InDret, 1, pp. 1-36.

SPINDLER, G. (2012), "Implicaciones para los servicios de contenidos digitales de la Propuesta de Reglamento sobre un Derecho Común de Compraventa", en CÁMARA LAPUENTE, S. (dir.) y ARROYO AMAYUELAS, E. (coord.), La revisión de las normas europeas y nacionales de protección de los consumidores, Cizur Menor, Civitas, pp. 457-470. 